\title{
Slantlet transform used for faults diagnosis in robot arm
}

\author{
Muhamad Azhar Abdilatef Alobaidy ${ }^{1,2}$, Jassim Mohammed Abdul-Jabbar ${ }^{1}$, Saad Zaghlul Al-khayyt ${ }^{2}$ \\ ${ }^{1}$ Department of Computer Engineering, College of Engineering, University of Mosul, Mosul, Iraq \\ ${ }^{2}$ Department of Mechatronics Engineering, College of Engineering, University of Mosul, Mosul, Iraq
}

\begin{tabular}{|c|c|}
\hline Article Info & ABSTRACT \\
\hline Article history: & The robot arm systems are the most target systems in the fields of faults \\
\hline Received Aug 20, 2021 & $\begin{array}{l}\text { detection and diagnosis which are electrical and the mechanical systems in } \\
\text { many fields. Fault detection and diagnosis study is presented for two robot }\end{array}$ \\
\hline Revised Oct 24, 2021 & arms. The disturbance due to the faults at robot's joints causes oscillations at \\
\hline Accepted Nov 25, 2021 & $\begin{array}{l}\text { the tip of the robot arm. The acceleration in multi-direction is analysed to } \\
\text { extract the features of the faults. Simulations for planar and space robots are }\end{array}$ \\
\hline Keywords: & $\begin{array}{l}\text { presented. Two types of feature (faults) detection methods are used in this } \\
\text { paper. The first one is the discrete wavelet transform, which is applied in }\end{array}$ \\
\hline Accuracy & many research's works before. The second type, is the Slantlet transform, \\
\hline DWT & multi-layer perceptron artificial neural network is used for the purpose of \\
\hline Faults diagnosis & faults allocation and classification. According to the obtained results, the \\
\hline LabVolt & Slantlet transform with the multi-layer perceptron artificial neural network \\
\hline MLP-ANN & appear to possess best performance $(4.7088 \mathrm{e}-05)$, lower consuming time \\
\hline Planer & $(71.017308 \mathrm{sec})$ and higher accuracy $(100 \%)$ than the results obtained when \\
\hline SLT & $\begin{array}{l}\text { applying discrete wavelet transform and artificial neural network for the } \\
\text { same purpose. }\end{array}$ \\
\hline
\end{tabular}

This is an open access article under the CC BY-SA license.

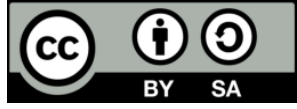

Corresponding Author:

Muhamad Azhar Abdilatef Alobaidy

Department of Mechatronics Engineering, Colege of Engineering

University of Mosul, Mosul, Iraq

Email: muhamad.azhar@umosul.edu.iq

\section{INTRODUCTION}

Robots that being developed in recent years and are now utilized in number of fields. They have been used in industries, militaries, medical equipment, and many other fields [1]. For most of these applications, it is recommended that the used robot must be safe and precise as much as possible. That because any failure in a robot can have a significant impact on the performance during work, resulting in poor results [1]-[4]. Condition monitoring for robots differs from that simple rotating gear due to their extremely sophisticated mechanics. To fulfil any given scenario for a robot, each joint in the robot's body will move at different angular speeds (and accelerations), demand different torques, and rotate at different angles. The mechanical or electrical impulses sent by the robot will be transitory, lasting only a few seconds. The signals generated by malfunctioning parts are non-stationary [5]. The fault diagnosis method normally consists of three steps: fault identification, which may indicate the presence of irregular behaviours, fault isolation, which determines the location and form of the failure that occurs, and finally fault analysis, which reveals the relationship between failure causes and symptoms [6], [7]

In 2011, Eski et al. [8] published a study that described an experimental investigation on a robot manipulator by using a neural network to analyse the vibration condition on joints. Each joint's noise and vibration were calculated. Then, to predict the servicing time, the relevant parameters are checked with a neural network predictor. Two types of neural predictors are used to find a stable and adaptive neural 
network structure. These two methods enhanced performance, allowing for the adoption of a rotated binary neural network (RBNN) form to forecast vibrations on industrial robots. In 2016, Jaber and Bicker [9] developed an intelligent condition monitoring system for industrial robot joints to detect the most common bearing failures, such as inner/outer race bearing faults. For precise defect diagnosis, the discrete wavelet transform (DWT) was utilized to perform time-frequency signal analysis. After that, an artificial neural network (ANN) was applied to classify the faults. Using the PUMA 560 robot, an experimental investigation setup was carried out. The standard deviation features were computed for multi-band frequency levels and used to design, train, and test the proposed neural network. The created approach was extremely accurate in diagnosing a variety of seeded robot defects. Lin and Boldbaatar [10] proposed a model-based fault accommodation control technique for biped robot locomotion with unknown uncertainties and faults, which relied on a recurrent wavelet elman neural network (RWENN) to achieve appropriate control with minimal output degradation. The adaptive laws of the RWENN-based fault accommodation regulation are derived using the Lyapunov theorem, ensuring the system's stability; a numerical comparison with other neuralnetwork-based control methods was utilized to illustrate its superiority. In 2019 Cho et al. [11], presented a method of fault detection using a special algorithm using neural network for robot manipulators. The study proposes a neural network-based fault detection approach that does not require the use of a physical robot model or acceleration. A neural network can be used to calculate the fault torque, allowing for successful defect identification and diagnosis.

According to the obtained results in the pre-mentioned studies, there is no single simulation study applying more than one technique for the purpose of faults detection and diagnosis. Due to that, no comparisons have been done between different techniques. Moreover, in the mentioned studies, only one type of fault in one location at a time is tested; there are no expectations for more types of faults on different locations. The pre-mentioned studies also give no focus on the consuming time. In addition, the Slantlet transform (SLT) [12]-[15], is not used yet for the faults diagnosis in robot arms. In this paper, two types of features (faults) detection methods are used for many faults in many locations at a time, the used methods are the DWT and the SLT. In the following sections, the robot arm simulation, DWT, SLT, and also the faults classification are explained deeply; also the results and discussion, conclusion and future works are included.

\section{ROBOT ARM SIMULATION}

A robot is a reprogrammable multifunctional manipulator that is programmed to move (materials, components, and tools). The robot arm system can be exposed to many problems, which can lead to failures or system faults [16]. Robots can malfunction due to human mistake, control panel issues, mechanical faults, power outages, and environmental variables. The main reason for preventing such failures is that they might result in human injury or death, as well as costly downtime. Positional error is responsible for half of all robot failures [17]. The motion of any robot arm is usually depends on the number of joints and their properties. Thus, there is a difference between the two and the three joints robot arms. Additional $\mathrm{z}$ dimension, which comes from the third joint is added, makes the robot arm's motion more flexible, but with some complexity in design, works and robot arm's kinematics equations. In this paper, two robot arms are presented using Matlab Simulink, to simulate real models. The first model is designed to simulate the planar robot arm (two joints robot arm), Figure 1. The second model is designed to simulate LabVolt 5150 robot arm Figure 2 and Figure 3.

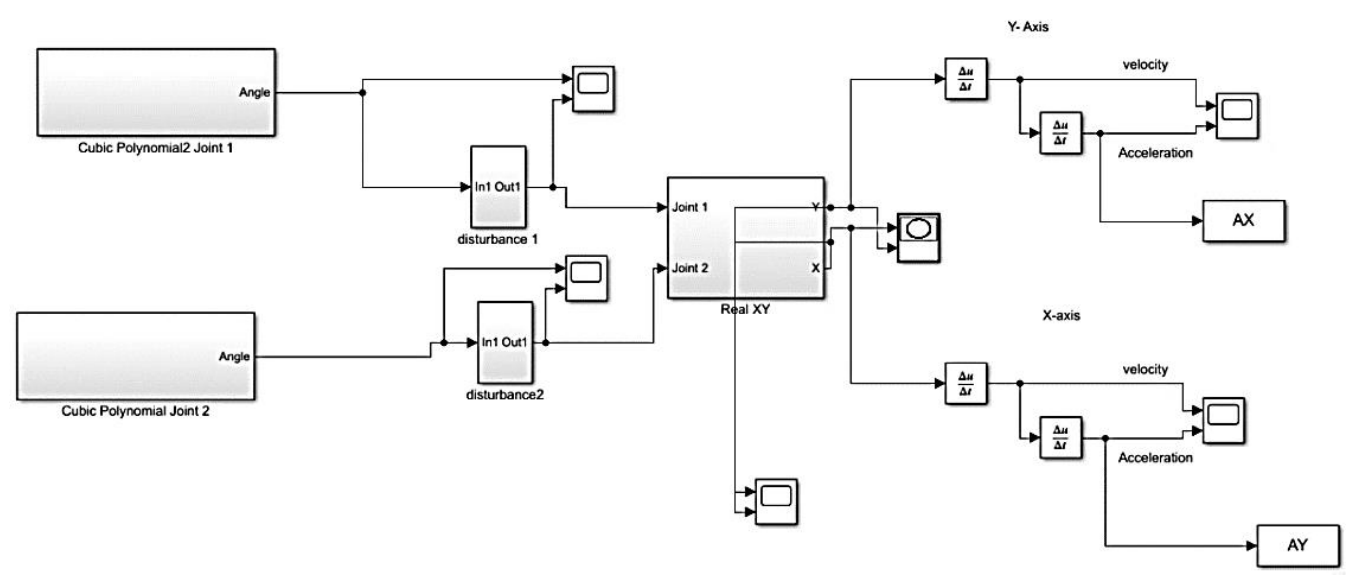

Figure 1. Two joints robot arm simulation model (planer robot arm) 


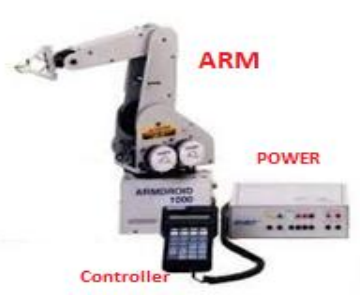

Figure 2. LabVolt 5150 robot arm

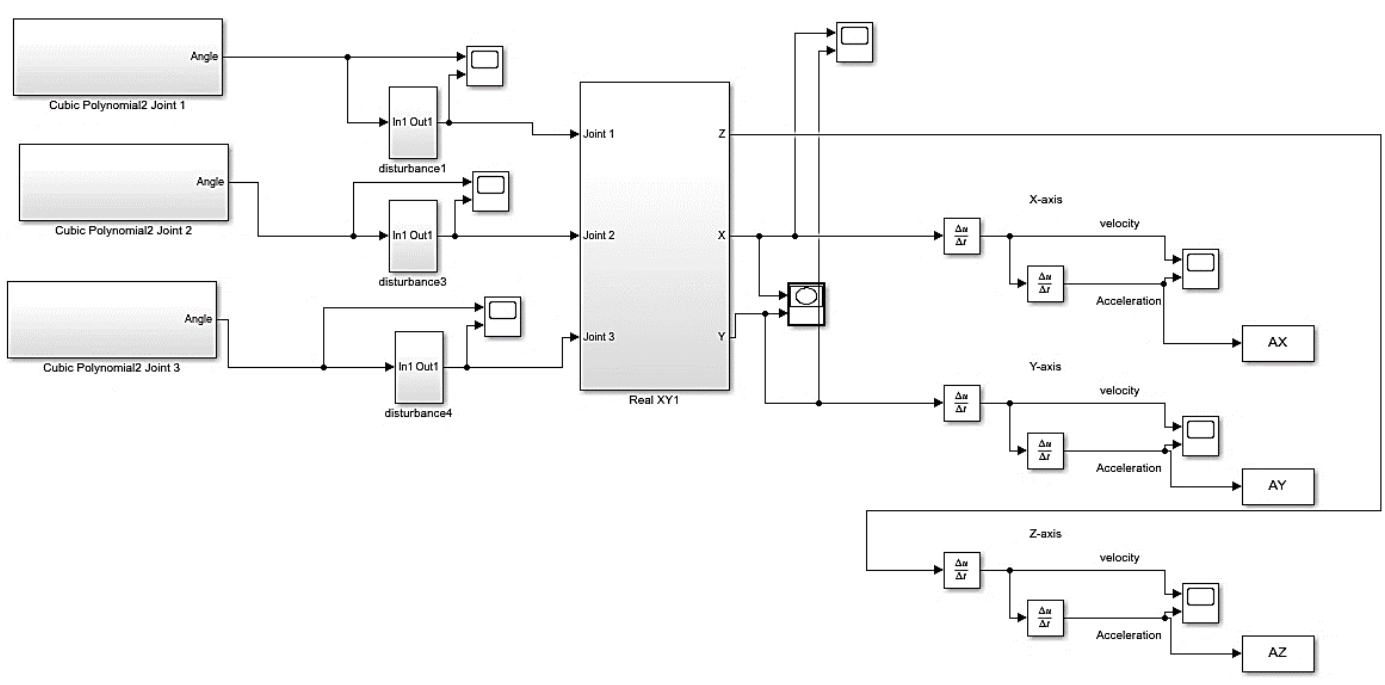

Figure 3. LabVolt robot arm simulation

In the two simulations, a cubic trajectory generation block Figure 4 is used representing the typical implementation case. A standard scope is connected to track the output signal. The original signals in the joints represent the joints positions. The suitable cubic polynomial has the form [18]:

$$
\theta(t)=\theta_{0}+\left(3 / t f^{2}\right)\left(\theta f-\theta_{0}\right) t^{2}-\left(2 / t f^{3}\right)\left(\theta f-\theta_{0}\right) t^{3}
$$

where;

$\theta_{0}:$ initial position

$\theta f:$ final position

$t f$ :time duration for motion

The signals are then merged with an external signal as a disturbance model, which consists of a repeated stair sequence with a gain. The purpose of using the disturbance model is to used the robot signals faulty. The signal at each joint of the robot arm is to be converted into Cartesian coordinates using the forward kinematics equations. The forward kinematics equations for the planner are:

$$
\begin{aligned}
& X=L_{1} \cos \theta+L_{2} \operatorname{Cos}\left(\theta_{1}+\theta_{2}\right) \\
& Y=L_{1} \operatorname{SIN} \theta+L_{2} \operatorname{SIN}\left(\theta_{1}+\theta_{2}\right)
\end{aligned}
$$

While, the forward kinematics for LabVolt 5 robot arm are:

$$
\begin{aligned}
& X=\operatorname{COS}_{1}\left[L_{1} \operatorname{Cos} \theta_{2}+L_{2} \operatorname{Cos}\left(\theta_{1}+\theta_{2}\right)\right] \\
& Y=L_{1} \operatorname{SIN} \theta_{2}+L_{2} \operatorname{SIN}\left(\theta_{2}+\theta_{3}\right) \\
& Z=\operatorname{SIN} \theta_{1}\left[L_{1} \operatorname{Cos} \theta_{2}+L_{2} \operatorname{Cos}\left(\theta_{2}+\theta_{3}\right)\right]
\end{aligned}
$$

Where; $\mathrm{L}_{1}$ and $\mathrm{L}_{2}$ are the lengths of link1 and link 2; respectively. 
For noisy or faulty signals, it is preferred to deal with the acceleration signals (the $2^{\text {nd }}$ order derivation of positions) because they are more sensitive to both time- and frequency-changes. In this paper, the detected acceleration signals are to be registered and diagnosed with the wavelet transform, and the process is repeated with SLT. ANN is then used to classify the defective signals. The most detected faulty signals occur because of the unstable torque or force applied to the joints or because of high loads, which lead to additional noisy signals, appear as oscillations [17], [19]. The acceleration is expected to be easily read since accelerometer sensors are used in the majority of real-world recent works [4]. A noisy signal is produced in this simulation by adding a disturbance signal at joints. This condition causes the original signals to be disrupted, resulting in the output of a defective signal. The ANN is then applied for the purpose of fault's classification.

\section{DISCRETE WAVELET TRANSFORM}

The wavelet is considered as one of the recent approaches for signal transformation, that has a wide range of applications [20]. The wavelet transform is viewed as a solution to the shortest time fourier transform (STFT)'s problems. As shown in Figure 4, it considers a variety of windows with varying scales and widths (7). In this way, the wavelet transform will divide data into several frequency components and investigate each one separately [16], [20].

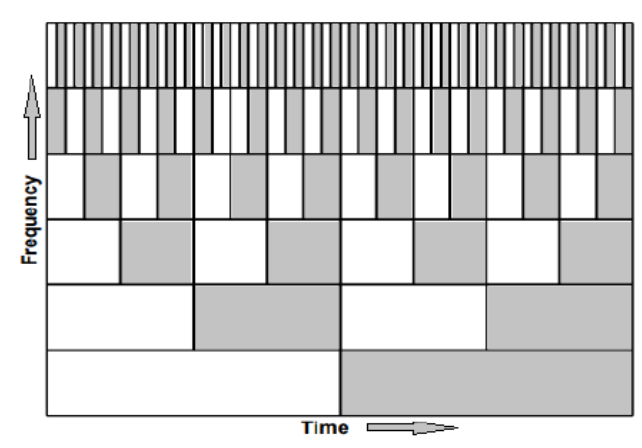

Figure 4. Wavelet time-scale representation [16]

$$
\Psi / a, b(t)=\frac{1}{\sqrt{a}} \Psi\left(\frac{t-b}{a}\right)
$$

The wavelet transform is used to decompose non-stationary time series domains into frequencytime domains in a variety of fields [21]. This concept's mean is a little wave, which is an oscillatory function for a zero average that is localized in a minor span. Wavelet coefficients can be manipulated in a frequencybased manner, then, inverted to a time-based representation. The mother wavelet function can be modified to generate other daughter wavelet functions, forming the wavelet family group. Each daughter wavelet function is a moved-extended, or a moved-compressed version of the mother wavelet [21]. The wavelet transform is divided into two types: continuous and discrete. Haar and Daubechies are usual forms of discrete wavelet that are discontinues in time, possessing Shannon discontinues in frequency [22]. According to the applications' purposes, discrete wavelet transforms is used. The impracticality and redundancy of continues wavelet transform (CWT) are both familiar problems; the first is because both parameters are constant, while the second is due to the wavelet's existence. During the wavelet calculation, when the continuously-scalable function is continuously shifted the over the signal to determine the correlation between them, the stated redundancy problem occurs. As a result, the wavelet coefficients must be extremely redundant [23]. The DWT is a type of wavelet that is developed by sampling the wavelet coefficients to overcome this problem. The discrete wavelet is not continuously scalable or translatable, but it can be scaled and translated in discrete steps. To accomplish this, the wavelet equation is modified as shown in (8).

$$
\Psi_{j^{\prime} k}(t)=\frac{1}{\sqrt{S_{0}^{J}}} \Psi\left(\frac{t-k T_{0} s_{0}^{J}}{s_{0}^{J}}\right)
$$


Where; $(\mathrm{j}, \mathrm{k})$ are integers, and $(\mathrm{s} 0>1)$ is a constant dilation phase. The dilation phase determines the translation factor $S_{0}$ in (8). $S_{0}$ is usually set to two such that the frequency axis sampling leads to dyadic sampling. The translation factor is normally set to one; this results in a dyadic sampling of the time axis. $S=2^{j}$, $\mathrm{t}=\mathrm{k}^{*} 2^{\mathrm{j}}$. In this paper, Daubechies four (DB4), which is a type of DWT, is used for the purpose of fault detection in robot arm signals (trajectory). This type is proposed to be used because of the limited period of time used to complete the trajectory (path) of the used simulated robot arm. Five levels are analyzed to reach the suitable banks' filters for the purpose of features extraction. Figure 5, D0-D4 represent the features for faults diagnosis, the high frequencies, which represent the high pass filters' (HPFs) outputs, are depended. While the low frequencies from the low pass filters (LPFs) are not used.

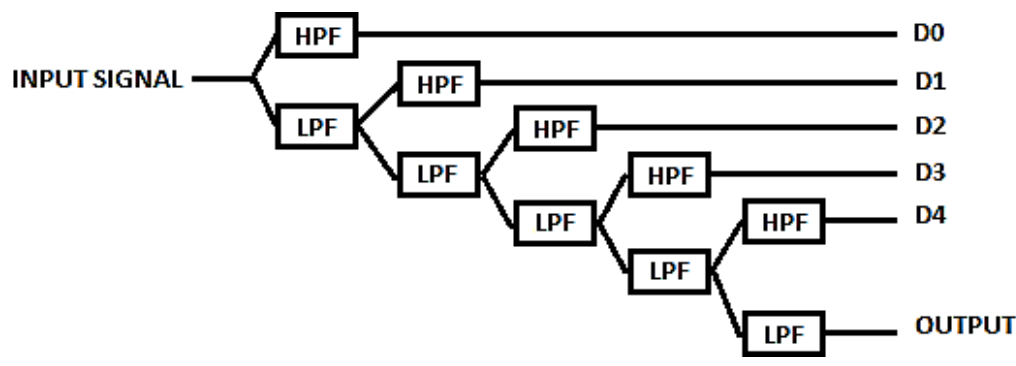

Figure 5. Wavelet five level opened diagram

\section{SLANTLET TRANSFORM}

The DWT is a teqniche used especially for multi-resolution analytic applications. It has changeable windows that are short at high frequencies and long at low frequencies [24]. To solve one of DWT's weaknesses, the inability to construct an ideal discrete time basis for a finite number of zero moments, Selesnick invented the SLT in 1999, a type of filter comparable to DWT that outperforms DWT by increasing time localization qualities [12]. SLT is a high-resolution multi-resolution approach that uses piecewise linear data. SLT, is like DWT, in orthogonality and capability of decomposition at several resolutions. SLT filters are commonly implemented as a tree structure with filter bank iteration, whereas DWT filters are typically built as a tree structure without filter bank iteration [25], [26]. SLT is just a series of parallel filters built from an orthogonal DWT with a time-localization improvement [24], as shown in Figure 6. In [27], the second scale's coefficients of SLT filter bank were calculated with their. Sum-ofpowers-of-two (SOPOT) representations, while the third scale coefficients of SLT filter bank were calculated in (9) and (10) [28]. In such work, the same coefficients for second scales were obtained. Those coefficients of the SLT filters' bank $\left(\mathrm{F}_{2}(\mathrm{z}), \mathrm{G}_{2}(\mathrm{z})\right.$, and $\mathrm{z}^{-3} \mathrm{G}_{1}(1 / \mathrm{z})$ are used in this paper for the purpose of feature detection (fault diagnosis), while $\mathrm{H}_{2}(\mathrm{z})$ filter which represents the LPF is not used, because of its inefficient coefficients. These measured and used coefficients were relied on and used. The coefficients of the used filters are convoluted with the robot arm's output acceleration signals of each joint to extract the required features for fault diagnosis. These diagnosed features are then used as inputs for an ANN to identify the faults according to their types and locations. The coefficients of the $2^{\text {nd }}$ scale SLT's filter bank are shown in Tables 1-4.

$$
\begin{aligned}
& g_{i}(x)=\left\{\begin{array}{cc}
a_{0 \prime 0}+a_{1 / 0} & \text { for } n=0 \ldots 2^{j} \\
a_{1 / 0}+a_{1^{\prime} 1} *\left(n-2^{j}\right) & \text { for } n=2^{j} \ldots 2^{j+1}-1
\end{array}\right. \\
& \mathrm{m}=2^{\mathrm{j}} \\
& \left.\mathrm{S}_{1}=6^{*} \sqrt{(\mathrm{m}) /\left(\left(\mathrm{m}^{\wedge} 2\right)-1\right)\left(4 \mathrm{~m}^{\wedge} 2-1\right)}\right) \\
& \mathrm{t}_{1}=2 * \sqrt{3 /\left(\mathrm{m}\left(\mathrm{m}^{2}-1\right)\right.} \\
& \mathrm{S}_{0}=-\mathrm{S}_{1} *(\mathrm{~m}-1) / \\
& \mathrm{t}_{0}=\left((\mathrm{m}+1)(\mathrm{s} 1 / 3)-\mathrm{mt}_{1}\right)((\mathrm{m}-1) / 2 \mathrm{~m}) \\
& \mathrm{a}_{0 \prime 0}=\left(\mathrm{s}_{0}+\mathrm{t}_{0}\right) / 2 \\
& \mathrm{a}_{1 / 0}=\left(\mathrm{s}_{0}-\mathrm{t}_{0}\right) / 2 \\
& \mathrm{a}_{0 / 1}=\left(\mathrm{s}_{1}+\mathrm{t}_{1}\right) / 2 \\
& a_{1 / 1}=\left(s_{1}-t_{1}\right) / 2
\end{aligned}
$$




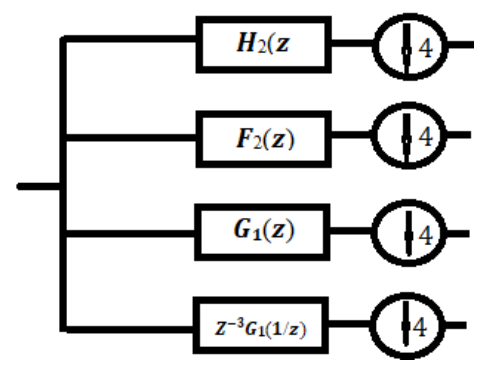

Figure 6. Second scale SLT filter bank structure

Table 1. SLT second scale $\mathrm{H}_{2}(\mathrm{z})$ filter's initial coefficients

\begin{tabular}{ccccccccc}
\hline SLT Filters & $\mathrm{h}(0)$ & $\mathrm{h}(1)$ & $\mathrm{h}(2)$ & $\mathrm{h}(3)$ & $\mathrm{h}(4)$ & $\mathrm{h}(5)$ & $\mathrm{h}(6)$ & $\mathrm{h}(7)$ \\
\hline Coefficients & 0.2698 & 0.3948 & 0.5198 & 0.6448 & 0.2302 & 0.1052 & -0.0198 & -0.1448 \\
\hline
\end{tabular}

Table 2. SLT second scale F2 (z) filter's initial coefficients

\begin{tabular}{ccccccccc}
\hline SLT Filters & $\mathrm{h}(0)$ & $\mathrm{h}(1)$ & $\mathrm{h}(2)$ & $\mathrm{h}(3)$ & $\mathrm{h}(4)$ & $\mathrm{h}(5)$ & $\mathrm{h}(6)$ & $\mathrm{h}(7)$ \\
\hline Coefficients & -0.0825 & -0.1207 & -0.1589 & -0.1971 & 0.7533 & 0.3443 & -0.0648 & -0.4738 \\
\hline
\end{tabular}

Table 3. SLT second scale Initial coefficients of G1(z) filter

\begin{tabular}{ccccc}
\hline SLT Filter & $\mathrm{h}(0)$ & $\mathrm{h}(1)$ & $\mathrm{h}(2)$ & $\mathrm{h}(3)$ \\
\hline Coefficients & -0.5117 & 0.8279 & -0.1208 & -0.1954 \\
\hline
\end{tabular}

Table 4. SLT second scale initial coefficients of G1(z) filter $\left(\boldsymbol{Z}^{-}(\mathbf{1} / \mathbf{z})\right)$

\begin{tabular}{ccccc}
\hline SLT Filter & $\mathrm{h}(0)$ & $\mathrm{h}(1)$ & $\mathrm{h}(2)$ & $\mathrm{h}(3)$ \\
\hline Coefficients & -0.1954 & -0.1208 & 0.8279 & -0.5117 \\
\hline
\end{tabular}

\section{FAULTS CLASSIFICATION}

The mostly used process for the purpose of separation and classification in recent studies, is the ANN. Jaber [4], [5] the multi- layer perceptron (MLP) with one hidden layer is used, refereeing to that and according to their accurate results obtained beside of its similarity of this works, the same ANN with some modifications, is used here. In this work, two simulations are designed and tested, the first one is a planer robot arm that has two joints, while the second simulation is also a robot arm but with three joints. The faults are supposed to be happened in joints, each joint can be exposed to problems, which usually lead to faults, causing a motion's failure in robot. Ten inputs/four outputs MLP is designed for the planer robot arm, and fifteen inputs/eight outputs is designed for the LabVolt (three joints example) robot arm manipulator, Table 5. The data is divided according to that $70 \%$ for training, $15 \%$ for validation and $15 \%$ for testing process. The confusion matrix, which is calculated to show the adjacency between the output and targets in addition to the system accuracy.

Table 5. MLP-ANN characteristics

\begin{tabular}{|c|c|c|c|}
\hline & Characteristics & Planner robot arm & LabVolt robot arm \\
\hline 1 & Number of input layer neurons & 10 & 15 \\
\hline 2 & Number of hidden layer neurons & 1 & 1 \\
\hline 3 & Number of output layer neurons & 4 & 8 \\
\hline 5 & Hidden layer activation function & Bayesian Regularization & Bayesian Regularization \\
\hline 6 & Output layer activation function & Linear & Linear \\
\hline 7 & Learning rate & 0,05 & 0,05 \\
\hline 8 & Minimum performance gradient & $1.00 \mathrm{e}-07$ & $1.00 \mathrm{e}-07$ \\
\hline 9 & Maximum number of epoch & 5000 & 5000 \\
\hline
\end{tabular}

\section{RESULTS AND DESCUTION}

In this section, a faults diagnosis study is presented; two methods of fault detection and diagnosis (DWT and SLT) are applied for the acceleration output signals of two robot arm simulations (Planer and 
LabVolt), Figure 7. Both of robot arm models are built using Matlab Simulink. As mentioned before, disturbance signal is added to the joints of the robot arms joints. Many cases are supposed to be happened; in the planer simulation four cases are expected to be happened according to the following scenario:

- One of the two joints are disturbed (two cases)

- Both of the joints disturbed (one case)

- Both of the joints are healthy (one case)

In the second designed simulation, which represent LabVolt industrial robot arm (three joints robot arm), eight cases can be expected to be happened when disturbance signals have to be added according to the following scenario:

- One joint disturbed signal (three cases)

- $\quad$ Two joints are disturbed (three cases)

- All signals' joints are healthy (one case)

- All signals' joints are disturbed (one case)

Each of these cases, for the both simulations, is referred to a motion situation which represents signals of acceleration in ( $\mathrm{x}, \mathrm{y})$ directions for the planner, and in $(\mathrm{x}, \mathrm{y}, \mathrm{z})$ directions for the LabVolt robot arm. These cases can indicate if the motion is noisy (distorted signal) or not, specifying the location of disturbance if exists. The recorded initial and final positions for planer are $\left[-15^{\circ}, 15^{\circ}\right]$ and $\left[60^{\circ}, 75^{\circ}\right]$; respectively, while for LabVolt robot arm are $\left[-15^{\circ},-15^{\circ}, 15^{\circ}\right]$ and $\left[60^{\circ}, 60^{\circ}, 75^{\circ}\right]$; respectively. At the beginning, the robot arm simulation is run, for a duration time, the acceleration signals are recorded using $0.001 \mathrm{sec}$. as a simulation time per wall clock and $3.973 \mathrm{sec}$. for all [1], [5]. Each recorded signal consists of (3973) samples in a raw, representing the three-directions accelerations (Ax, Ay, Az). After the completion of data recording, the features detection process is taken a place. A five-level decomposition with DB4 filters is applied for the data, it gave better and stable results with more accuracy than others (DWT with less than five number of level decomposition). Thus by using wavelet for the planer robot arm ( $\mathrm{x}$, and $\mathrm{y}$ ), ten output coefficients are resulted, while fifteen coefficients are produced for the LabVolt robot arm simulation (x, y, and $\mathrm{z}$ ). Each of the resulting wavelet coefficient consists of (1x1990) samples. As mentioned before, four cases are expected to be happened due to the faults with their locations. According to that, each one of the ten coefficients $\left(\mathrm{D}_{0}-\mathrm{D}_{10}\right)$, will be produced four times (four cases). These coefficients are then concatenated as shown in Figure 7. After concatenation, ten inputs of 1x7960 samples (4x1990) will be applied as an input to the ANN for the purpose of faults classification according to their locations. The MLP is used for this purpose (as in section 5, Table 5). The same procedure is repeated for the LabVolt robot arm simulation, but with three signals in the (x,y, and $\mathrm{z}$ ) directions. The results of these experiments are recorded in Table 6.

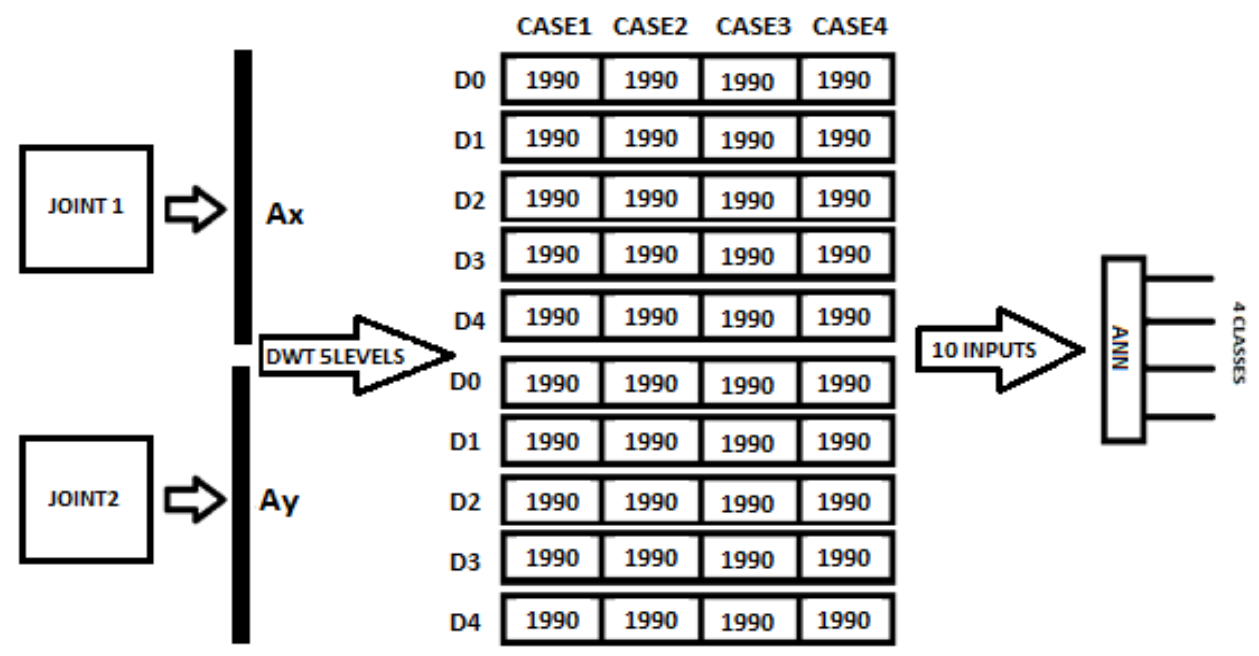

Figure 7. Planner robot arm's faults diagnosis process

As shown in Figure 7, four outputs from the ANN will represent four classes. when the inputs to the ANN are related to data in case 1, then the ANN output will be [ $\left[\begin{array}{llll}1 & 0 & 0 & 0\end{array}\right]$, while when they are related to cases

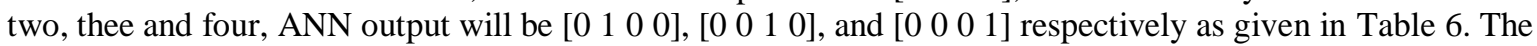
same procedure is used for the LabVolt (three joints) robot arm simulation, but with differences of fifteen 
inputs and eight classes (ANN outputs), Table 7. As mentioned in section 5, the MLP-ANN is used for the purpose of features (faults) classification. The Bayesian regularization activation function is used for the hidden layer that has 18 neurons (the best-experimented case), and the linear activation function is used for the output layer. The accuracy of the system reaches $93.9 \%$ for the planner robot arm, while it reaches $88.6 \%$ for the LabVolt robot arm using DWT.

Table 6. MLP-ANN classification for planar cases

\begin{tabular}{ccc}
\hline Cases & Output & Fault location \\
\hline 1 & {$\left[\begin{array}{llll}1 & 0 & 0 & 0\end{array}\right]$} & No faults (Healthy) \\
2 & {$\left[\begin{array}{llll}0 & 1 & 0 & 0\end{array}\right]$} & Joint 1 (Shoulder) \\
3 & {$\left[\begin{array}{llll}0 & 0 & 1 & 0\end{array}\right]$} & Joint 2 (Arm)7 \\
4 & {$\left[\begin{array}{llll}0 & 0 & 0 & 1\end{array}\right]$} & Joint $1 \quad \& 2$ \\
\hline
\end{tabular}

Table 7. MLP-ANN classification LabVolt cases

\begin{tabular}{|c|c|c|}
\hline Cases & Output & Fault location \\
\hline 1 & {$\left[\begin{array}{llllllll}1 & 0 & 0 & 0 & 0 & 0 & 0 & 0\end{array}\right]$} & No faults (Healthy) \\
\hline 2 & {$\left[\begin{array}{llllllll}0 & 1 & 0 & 0 & 0 & 0 & 0 & 0\end{array}\right]$} & Joint 1 (Base) \\
\hline 3 & {$\left[\begin{array}{llllllll}0 & 0 & 1 & 0 & 0 & 0 & 0 & 0\end{array}\right]$} & Joint 2 (Shoulder) \\
\hline 4 & {$\left[\begin{array}{llllllll}0 & 0 & 0 & 1 & 0 & 0 & 0 & 0\end{array}\right]$} & Joints $1 \& 2$ \\
\hline 5 & {$\left[\begin{array}{llllllll}0 & 0 & 0 & 0 & 1 & 0 & 0 & 0\end{array}\right]$} & Joint 3 (Arm) \\
\hline 6 & {$\left[\begin{array}{llllllll}0 & 0 & 0 & 0 & 0 & 1 & 0 & 0\end{array}\right]$} & Joint $1 \& 3$ \\
\hline 7 & {$\left[\begin{array}{llllllll}0 & 0 & 0 & 0 & 0 & 0 & 1 & 0\end{array}\right]$} & Joints $2 \& 3$ \\
\hline 8 & {$\left[\begin{array}{llllllll}0 & 0 & 0 & 0 & 0 & 0 & 0 & 1\end{array}\right]$} & Joints $1,2, \& 3$ \\
\hline
\end{tabular}

The results of these experiments are recorded in Table 8. In the second part, the SLT filters ( $\mathrm{F}_{2}(\mathrm{z})$, $\boldsymbol{G}_{\mathbf{1}}(\mathbf{z})$, and $\left(\boldsymbol{Z}^{-\mathbf{3}} \boldsymbol{G}_{\mathbf{1}}(\mathbf{1} / \mathbf{z})\right)$ are used instead of the DWT for the purpose of feature (faults) detection. The acceleration's signals those comes from coordinates $(\mathrm{x}$, and $\mathrm{y})$ in planar and ( $\mathrm{x}, \mathrm{y}$ and $\mathrm{z}$ ) in LabVolt are convoluted with the coefficients of these banks filters of the SLT [25]. The resulted features are used as inputs for the MLP-ANN to classify the faults according to their types and locations. The accuracy by using these filters instead of the DWT is increased to be $100 \%$ for the planar and $99.9 \%$ for the LabVolt robot arm, Table 9.

Table 8. DWT (5 level Db4) and ANN for faults' diagnosis in robot arms

\begin{tabular}{ccccc}
\hline & Robot arm & Performance (MSE) & Time of Process (sec) & Accuracy \\
\hline 1 & Planar & 0.0259 & 3075.551457 & $93.9 \%$ \\
2 & LabVolt & 0.0282 & 16369.924428 & $88.6 \%$ \\
\hline
\end{tabular}

Table 9. SLT 2 scale and ANN for faults' diagnosis in robot arms

\begin{tabular}{ccccc}
\hline & Robot arm & Performance (MSE) & Time of Process(sec) & Accuracy \\
\hline 1 & Planar & $4.7088 \mathrm{e}-05$ & 71.017308 & $100 \%$ \\
2 & LabVolt & $8.3969 \mathrm{e}-05$ & 26.460 & $99.9 \%$ \\
\hline
\end{tabular}

According to the given results in Tables 8 and 9, it is clear to proof that the SLT filters are much better than the DWT for the faults' diagnosis in robot arms, for both planar and three joints robot arms. Besides the accuracy, the processing time needed for the SLT is smaller than the time needed for the DWT, also the number of iterations is reduced for reaching the results with better performance.

\section{CONCLUSION}

Nowadays, faults diagnosis is a very important field to focus on and perform many studies about. The signal of robot arm tip's accelerations always give the required information about faults. The DWT was used in many works for the purpose of faults diagnosis in a robot arm, but only for one joint. In this paper many faulty joints have been studied at the same time. Two methods have been used; namely, the DWT and the SLT filters. The features of the faults at joints have been extracted clearly from coefficients of the two methods. More than one fault at the same time in different joints have been detected and isolated in the simulation. The suggested methods have succeeded in detecting and isolating the faults in robot arm joints 
which are moving in short time duration tasks. The results of SLT have shown better accuracy, smaller time of process, better performance, and lesser complexity than the DWT. Thus, the method of using both (SLT and MLP-ANN) is suggested to be used instead of (DWT and MLP-ANN) for fault diagnosis, especially in robotics systems.

\section{ACKNOWLEDGEMENTS}

The authors would like to express their gratitude to the faculty and staff of the University of Mosul's College of Engineering, especially the departments of computer engineering and mechatronics engineering, for their contributions to this research.

\section{REFERENCES}

[1] M. H. Terra and R. Tinós, "Fault detection and isolation in robotic manipulators via neural networks: A comparison among three architectures for residual analysis," Journal of Robotic Systems, vol. 18, no. 7, pp. 357-374, 2001, doi: 10.1002/rob.1029.

[2] J. Halme, "Condition monitoring of a material handling industrial robot," in Condition Monitoring and Diagnostic Engineering Management: COMADEM 2006, Luleå University of Technology, pp. 415-424, 2006.

[3] D. Baleanu, "Wavelet Transform and Some of Its Real-World Applications," BoD-Books, 2015, doi: 10.5772/59743.

[4] A. A. Jaber, "Design of an intelligent embedded system for condition monitoring of an industrial robot,". Springer 2016.

[5] A. A. Jaber and R. Bicker, "Industrial robot fault detection based on wavelet transform and LabVIEW," in IEEE First International Conference on Systems Informatics, Modelling and Simulation, Sheffield, United Kingdom, 2014, pp. 21-31, doi: 10.1109/SIMS.20014.27.

[6] S. Hara, Y. Kawahara, T. Washio, P. von Bünau, T. Tokunaga, and K. Yumoto, "Separation of stationary and non-stationary sources with a generalized eigenvalue problem," Neural Networks, vol. 33, pp. 7-20, 2012, doi: 10.1016/j.neunet.2012.04.001

[7] L. M. Capisani, A. Ferrara, A. F. de Loza, and L. M. Fridman, "Manipulator Fault Diagnosis via Higher Order Sliding-Mode Observers," IEEE Transactions on Industrial Electronics, vol. 59, no. 10, pp. 3979-3986, 2012, doi: 10.1109/tie.2012.2189534.

[8] I. Eski, S. Erkaya, S. Savas, and S. Yildirim, "Fault detection on robot manipulators using artificial neural networks," Robotics and Computer-Integrated Manufacturing, vol. 27, no. 1, pp. 115-123, 2011, doi: 10.1016/j.rcim.2010.06.017.

[9] A. A. Jaber and R. Bicker, "Industrial robot backlash fault diagnosis based on discrete wavelet transform and artificial neural network," American Journal of Mechanical Engineering, vol. 4, no. 1, pp. 21-31, 2016, doi: 10.12691/ajme-4-1-4.

[10] C.-M. Lin and E.-A. Boldbaatar, "Fault Accommodation Control for a Biped Robot Using a Recurrent Wavelet Elman Neural Network," IEEE Systems Journal, vol. 11, no. 4, pp. 2882-2893, 2017, doi: 10.1109/jsyst.2015.2409888.

[11] C. N. Cho, J. T. Hong, and H. J. Kim, "Neural Network Based Adaptive Actuator Fault Detection Algorithm for Robot Manipulators," Journal of Intelligent \& Robotic Systems, vol. 95, no. 1, pp. 137-147, Jul. 2019, doi: 10.1007/s10846-018-0781-0.

[12] I. W. Selesnick, “The slantlet transform," IEEE Transactions on Signal Processing, vol. 47, no. 5, pp. 1304-1313, 1999, doi: $10.1109 / 78.757218$.

[13] G. Panda and S. K. Meher, "An Efficient Approach to Signal Compression using Slantlet Transform," IETE Journal of Research, vol. 46, no. 5, pp. 299-307, 2000, doi: 10.1080/03772063.2000.11416169.

[14] R. T. Mohammed and B. E. Khoo, "Image watermarking using slantlet transform," 2012 IEEE Symposium on Industrial Electronics and Applications. IEEE, 2012, doi: 10.1109/isiea.2012.6496644.

[15] M. Maitra and A. Chatterjee, "A Slantlet transform based intelligent system for magnetic resonance brain image classification," Biomedical Signal Processing and Control, vol. 1, no. 4, pp. 299-306, 2006, doi: 10.1016/j.bspc.2006.12.001.

[16] M. A. Alobaidy, D. J. Abdul-Jabbar, and S. Al-khayyt, "Faults Diagnosis in Robot Systems: A Review," Al-Rafidain Engineering Journal (AREJ), vol. 25, no. 2, pp. 166-177, 2020, doi: 10.33899/rengj.2020.127782.1051.

[17] S. Z. S. Al-Khayyt, "Tuning PID Controller by Neural Network for Robot Manipulator Trajectory Tracking," Al-Khwarizmi Engineering Journal, vol. 9, no. 1, pp. 19-28, 2013.

[18] P. Zhao, Y. Zhou, and R. Zhou, "A New Trajectory Optimizing Method Using Input Shaping Principles,” Shock and Vibration, vol. 2018, pp. 1-11, 2018, doi: 10.1155/2018/4173253.

[19] Y. Gao and R. J. Patton, "Application of wavelet analysis for performance monitoring and diagnosis of a hydraulic pump," IFAC Proceedings Volumes, vol. 36, no. 5, pp. 333-338, 2003, doi: 10.1016/s1474-6670(17)36513-8.

[20] M. Rhif, A. Ben Abbes, I. Farah, B. Martínez, and Y. Sang, "Wavelet Transform Application for/in Non-Stationary Time-Series Analysis: A Review," Applied Sciences, vol. 9, no. 7, p. 1345, 2019, doi: 10.3390/app9071345.

[21] A. Asuncion, "Signal Processing Applications of Wavelets, Information and Computer Science," University of California, Irvine, 2002.

[22] A. N. Akansu and E. Al, "Multiresolution signal decomposition: transforms, subbands, and wavelets,". Academic press, 2001.

[23] E. Khalastchi and M. Kalech, "On Fault Detection and Diagnosis in Robotic Systems," ACM Computing Surveys, vol. 51, no. 1, pp. 1-24, 2018, doi: 10.1145/3146389.

[24] M. I. Gursoy, A. S. Yilmaz, and S. V. Ustun, "A practical real-time power quality event monitoring applications using discrete wavelet transform and artificial neural network," Journal of Engineering Science and Technology, vol. 13, no. 6, pp. 1764-1781, 2018.

[25] G. Panda, P. K. Dash, A. K. Pradhan, and S. K. Meher, "Data compression of power quality events using the slantlet transform," IEEE Transactions on Power Delivery, vol. 17, no. 2, pp. 662-667, 2002, doi: 10.1109/61.997957.

[26] T. Z. Ismaeel, "Design \& Evaluation of a Steganography System for Speech Signal by Slantlet Transform," Diyala Journal of Engineering Sciences, vol. 5, no. 2, pp. 99-113, 2012.

[27] A. M. Jasim, H. M. Abd, and J. M. Abdul-Jabbar, "Complexity reduction of slantlet transform structure based on the multiplierless realization," Journal of Engineering Science and Technology, vol. 15, no. 3, pp. 1705-1718, 2020.

[28] H. N. Abdullah and S. A. Ali, "Implementation of 8-point Slantlet transform based polynomial cancellation coding-OFDM system using FPGA," 2010 7th International Multi- Conference on Systems, Signals and Devices. IEEE, 2010, doi: $10.1109 / \mathrm{ssd} .2010 .5585601$. 


\section{BIOGRAPHIES OF AUTHORS}
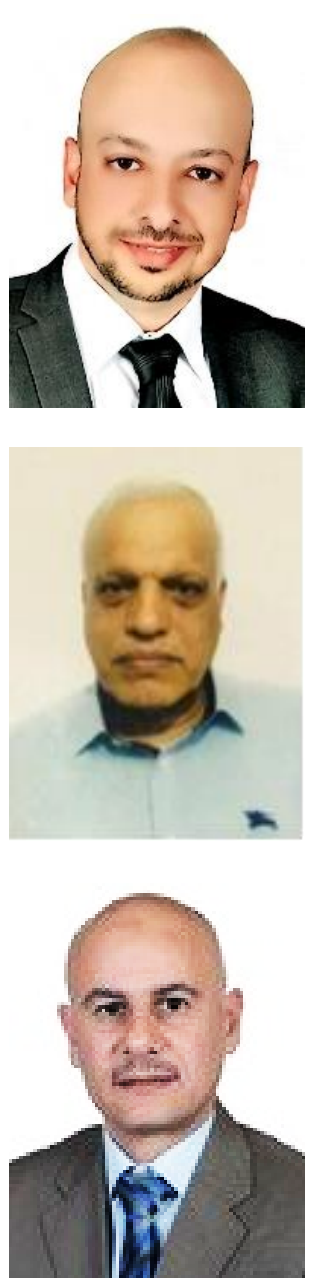

Muhamad Azhar Abdilatef Alobaidy (iD SC P received the B.Sc. degree in Computer Engineering from University of Mosul, Mosul, Iraq, in 2006, M.Sc. degree from Cankaya University, Turkey. Ph.D. candidate in Computer engineering Department, College of Engineering, University of Mosul. He is a lecturer at Mechatronics Engineering Department, University of Mosul. He was the head of Scientific affairs department at the presidency of the University of Mosul. Currently, he is the head of culture relationships division, University of Mosul. He has many published papers. He is a reviewer at edas. He can be contacted at email: muhamad.azhar@uomosul.edu.iq.

Jassim Mohammed Abdul-Jabbar (D) 8d SC P received the B.Sc. and M.Sc. degrees in Elictrical engineering from al Basra University Basra, Iraq. Ph.D. degree in Electrical engineering from Baghdad University, Baghdad, Iraq. He has been a professor of Digital Signal Processing in engineering. He was the Head of Electrical Engineering Department, College of Engineering, University of Basra, Basra, Iraq. He was the Head of Computer Engineering Department, College of Engineering, University of Mosul, Mosul, Iraq. He has many published papers. He can be contacted at email: drjssm@uomosul.edu.iq.

Saad Zaghlul Al-khayyt (D) 8d SC P received the B.Sc. and M.Sc. degrees in Mechanical engineering from Al-Nahreen University, in 1992, and 1995 respectly, Baghdad, Iraq, and the Ph.D. degree in Mechanical engineering from Russia. He has been an assistant professor of Mechatronics engineering in 2010. He is currently the Head of Mechatronis Engineering Department, College of Engineering, University of Mosul. He has many published papers. He can be contacted at email: Saeeds70@uomosul.edu.iq. 